\title{
Mutual Intercultural Relations among University Students in Canada
}

\section{Yongxia Gui*, Saba Safdar ${ }^{\dagger}$, John Berry $\ddagger$}

\author{
* Henan University of Economics and Law, China \\ ${ }^{\dagger}$ University of Guelph, Canada \\ *Queen's University \& National Research University Higher School of Economics, Canada \& \\ Russia
}

\section{Introduction}

In Canada, international students are defined as temporary residents who are legally authorized to study in Canada on a temporary basis (Citizenship and immigration Canada; CIC, n.d.). In December 2013, more than 304,000 international students were enrolled in Canada (CIC, 2014), with the largest numbers of international students being from China (CIC, 2015).

Increasing the number of international students is part of the government's plan to meet Canada's economic needs, to offset an aging population and low birthrate, and to sustain the workforce. International students bring with them many benefits to Canada, including increased revenues to educational institutions and communities and enhanced diversity to learning environments (CBIE, 2014). In addition to these benefits to Canada, international students also benefit from living in Canada. Their education and school experience can help them to better access the work force if they choose to remain in Canada; and they may have a better work opportunity in their country of origin due to their study experience abroad. However, studying overseas may also present many challenges, including the experience of acculturative stress which is related to forming friendship with local students, perception of discrimination, feelings of loneliness, and academic concerns (CBIE, 2014; Chavajay \& Skowronek, 2008; Safdar \& Berno, in press).

In a CBIE (2014) study, it was found that over one third of international students have difficulty forming friendships with Canadian students. Students identified various barriers for lack of integration including low attendance of Canadian students at on-campus diversity events and activities, which are heavily advertised for and attended by international students (CBIE, 2014). Low integration of international students with domestic students has been also reported in the U.S. (Gareis, 2012), U.K. (The Huffington Post U.K., 2013, as cited in CBIE, 2014), and Australia (Gresham \& Clayton, 2011, as cited in CBIE, 2014).

\section{Literature Overview}

Acculturation refers to "those phenomena which result when groups of individuals with different cultures come into contact, with subsequent changes in the original patterns of either or both groups, or in behavioural or psychological change in individuals from either or both groups" (Safdar, , Chuong, Lewis, 2013, p. 5). This is based on Redfield, Linton, and Herskovits' (1936) widely used definition of 
acculturation with an explicit reference to specific changes (i.e., behavioural and psychological) at the individual rather than group level. There are three important issues in understanding the process of acculturation: how individuals seek to acculturate; how well they adapt to intercultural living; and the relationship between these two issues.

The two-dimensional model of acculturation (Berry, 1980) considers that there are two relationships with respect to how acculturation takes place: the individual's relationship (i) with their heritage or ethnic culture and (ii) with the new or larger society. These two relationships are considered to be independent of each other. Generally positive or negative orientations to these issues intersect to define four acculturation strategies. A strong link to both groups is indicative of an integration strategy; links with neither group defines marginalization; an exclusive link with the dominant culture indicates assimilation; whereas exclusive link with the ethnic group indicates separation.

A second issue is that of how well adaptation takes place during acculturation; this has been defined in both psychological and sociocultural terms (Ward \& Kennedy, 1999). Psychological adaptation refers to feeling well (including high life satisfaction and self-esteem, and few psychological problems), while sociocultural adaptation (such as school adjustment and success in community life) refers to doing well in the new society. In addition to these two forms of adaptation, intercultural adaptation has been proposed by Berry (2015) to refer to relating well (including tolerance, accepting cultural differences, and a lack of prejudice and discrimination).

The third issue is whether there is any relationship between the acculturation strategies and adaptation. In much research on acculturation, the focus has been on comparing the benefits for adaptation across these four acculturation strategies. Findings generally show that the integration strategy has a positive relationship with people's psychological and sociocultural adaptation to the larger society, (Berry, 1997; Berry, Phinney, Sam, \& Vedder, 2006; Gui, Berry, \& Zheng, 2012; Nguyen \& Benet-Martinez, 2013; Safdar, Calvez, \& Lewis, 2012).

\section{Acculturation Research with International Students}

In early research with international students, their acculturation strategies were mostly measured using a one-dimensional scale, with high scores meaning a high level of assimilation to the dominant society, and low scores meaning a high level of keeping their own culture, i.e., separation (Ayres \& Mahat, 2012; Dao, Lee, \& Chang, 2007; Zhang \& Dixon, 2003). The problem with such measures, however, is that the meaning of acculturation corresponds only to the assimilation or separation ways; the other acculturation strategies proposed in the two-dimensional model are already theoretically excluded. In these earlier studies, it was reported that assimilation was positively related to attitudes toward seeking professional psychological help, confidence in mental health practitioners (Zhang \& Dixon, 2003), and positive health practices (Ayres \& Mahat, 2012). Assimilation was negatively related to depressive feelings (Dao et al., 2007), and perceived distress (Castillo, Conoley, \& Brossart, 2004). It is worth noting that these one-dimensional studies were conducted with international students in one social context (the USA).

\section{Acculturation Research with Dominant Groups}

Acculturation strategies can also be examined among the dominant group, using the two dimensions approach. These strategies have been termed acculturation expectations (Berry, 2003); here 
the focus is on their views about how non-dominant groups should acculturate. In this case the four strategies are termed multiculturalism, exclusion, melting pot, and segregation. To assess the dominant groups' views about their own willingness to change in order to accommodate the other groups now in their society, the concept of multicultural ideology was developed (Berry, Kalin, \& Taylor, 1977).

In the current study, we examine the views of both international and domestic students in Canada using the conceptual and empirical framework from the MIRIPS (Mutual Intercultural Relations in Plural Societies) project (http://www.victoria.ac.nz/cacr/research/mirips). We examine two hypotheses. First is the multiculturalism bypothesis which has shown that the greater cultural security persons felt, the more they held positive attitudes towards other ethnic groups and immigrants and the more they accepted multiculturalism (Berry et al., 1977; Berry \& Kalin, 1995; Esses, Hodson, \& Dovidio, 2003). For international students, the experience of discrimination in the new country serves to undermine their sense of security. When there is little discrimination, they will respond to the dominant group with more positive attitudes, and adopt a more positive acculturation strategy (i.e., integration or assimilation) toward the larger society. For Canadian students, this sense of security is expected to relate to their tolerance towards others.

Second is the integration hypothesis. This hypothesis is based on previous research (noted above) that has shown that there is a consistent pattern of relationships between a preference for the integration/multicultural strategy and individuals' better adaptation. For international students, those who adopt the integration strategy (involvement with both their own cultural group and with the larger Canadian society) will have better psychological, sociocultural and intercultural adaptation than those who adopt other acculturation strategies. For Canadian students, those who accept multiculturalism as a way for all groups to live in Canada will have greater psychological and intercultural adaptation.

\section{Method}

\section{Participants}

Two groups of students participated in the study: international students who are from China, and Canadian born and raised students. All students completed an online survey. The international students were recruited from several universities across Canada (except Quebec); Canadian students were recruited from an undergraduate course at a mid-size university and received a credit for their participation. More than 140 students completed the survey.

Some data were deleted based on results of the Social Desirability scale, missing information, and age. There were 57 international students: 29 male (50.9\%), 28 female (49.1\%); aged from 19 to 32 $(\mathrm{M}=26.0, \mathrm{SD}=3.0)$; they had lived in Canada on average 13.4 months ( $\mathrm{SD}=17.1)$. The Canadian sample was reduced in order to match as closely as possible the number, age and gender composition of the international student sample. There were 68 Canadian students: 31 male (45.6\%), 37 female (54.4\%); aged from 19 to $31(\mathrm{M}=21.9, \mathrm{SD}=2.1)$.

\section{Instruments}

Demographic variables including age, gender, length of time living in Canada and English Proficiency (for international students) were assessed. English Proficiency was measured using four items asking "how well do you understand/speak/read/write English". The psychological variables 
of security, perceived discrimination, acculturation, identity and adaptation were drawn from Berry and colleagues (2006). The source of the other scales are indicated below.

\section{Security scales}

The Cultural Security scale consists of five items, with a higher score meaning higher security about one's culture. A sample item is "There is room for a variety of languages and cultures in this country". It was administered only to the Canadian students (Cronbach alpha was .66).

Perceived Discrimination was used as a reversed measure of security; it assesses the perception of threat. It had five items assessing perceived frequency of being treated unfairly, being teased, threatened, or feeling unaccepted because of one's ethnicity (e.g., "I have been teased or insulted because of my ethnic background"). A higher score means more perceived discrimination. It was administered only to international students (Cronbach alpha was .84).

Perceived Consequences of Immigration. This scale was developed by Berry and Kalin (1995); it consists of eleven items. This scale assessed the perceived cultural, economic, and personal consequences of immigration. A sample item is "If more immigrants come to [country/region], there would be more unemployment" (reverse item). Higher scores indicate a positive attitude towards the consequences of immigration. The Cronbach alpha for this subscale was .65 for international students and .78 for Canadian students.

\section{Acculturation scales}

Three scales were used to assess acculturation: Acculturation attitudes and expectations; Cultural identities; and Peer contacts.

Acculturation Attitudes and Acculturation Expectations. The Acculturation Attitudes scale assessed the international students' four acculturation preferences for: Assimilation $(\alpha=.53)$, Integration $(\alpha=.71)$, Separation $(\alpha=.65)$, and Marginalization $(\alpha=.70)$. The items concern five domains of life: cultural traditions, language, marriage, social activities, and friends. The Acculturation Expectation scale consists of the same items but phrased for the expectations that Canadian students held for immigrants. The four corresponding acculturation expectations for Canadian students are: Melting pot $(\alpha=.65)$, Multiculturalism $(\alpha=.71)$, Segregation $(\alpha=.31)$, and Exclusion $(\alpha=.59)$. The Assimilation dimension for international students, and the Segregation and Exclusion dimensions for Canadian students were deleted from present study because of low reliability.

Cultural Identity. This scale has two subscales: Ethnic Identity (which was administered to international students) and National Identity (administered to both international students and Canadian students). Ethnic Identity was measured with eight items assessing ethnic affirmation, such as a sense of belonging and positive feelings about being an ethnic group member (eight items, e.g., "I feel that I am part of [ethnic] culture"; Cronbach alpha was .89). National Identity was assessed with measures of national affirmation and the importance of one's national identity (four items, e.g., "I am happy that I am Canadian"; Cronbach alpha was .88 for international students and .90 for Canadian students). A higher score means higher identification with one's ethnic group or Canada. 
Peer Contact. The Peer Contact scale was used as the indicator of students' social relationships, and was assessed using two items (each with three kinds of relationships): "How many close coethnic/national/other ethnic friends do you have", and "how often do you meet with your close coethnic/national/other ethnic friends?" The Co-ethnic Peer Contact items were only administered to international students.

\section{Adaptation scales}

Psychological adaptation was assessed by three scales: Self-esteem, Life satisfaction, and Psychological problems (reversed). Sociocultural adaptation was assessed by the Sociocultural competence scale. Intercultural adaptation was assessed by three scales: Multicultural ideology, Tolerance and Perceived consequences of immigration.

The Rosenberg Self-esteem Scale (RSES). The ten items of the Rosenberg Self-esteem Scale (Rosenberg, 1965) measures peoples' overall evaluation of their own worthiness as a human being. Cronbach alpha was .76 for international students and .89 for Canadian students.

The Satisfaction With Life Scale (SWLS). This five item scale is a measure of life satisfaction (Diener, Emmons, Larson, \& Griffin, 1985). High scores indicate high satisfaction with life. Cronbach alpha was .79 for international students and .83 for Canadian students.

Psychological Problems. The scale was developed by Berry et al. (2006). It measures Anxiety (seven items, Cronbach alpha was .84 for international students and .88 for Canadian students) and Depression (eight items, Cronbach alpha was .83 for international students and .89 for Canadian students). A higher score means more psychological problems.

Sociocultural Competence. This 20-item scale is an adaptation of the 29 items of Sociocultural Adaptation Scale (Ward \& Kennedy, 1999). International students (but not Canadian students) were asked to rate the amount of difficulty they experience in various social situations (e.g., getting used to the pace of life, going shopping). A higher score represents higher competence and less difficulty living in the new culture. Cronbach alpha was .96 in the present study.

Multicultural Ideology. This scale was developed by Berry et.al. (1977), and consists of ten items assessing the views held by the dominant group about how they think immigrants should acculturate, and how they themselves should change to accommodate other ethnic groups. A sample item is "It is best for Canada if all people forget their different ethnic and cultural backgrounds as soon as possible" (reverse item). A higher score indicates that a person is in favour of a multicultural society. The Cronbach alpha of this scale was .87 in the present study.

Tolerance. This scale consists of eleven items, which was based on Berry and Kalin's (1995) nineitem scale. The scale assesses one's willingness to accept individuals or groups that are culturally or racially different from oneself (e.g., "It is good to have people from different ethnic and racial groups living in the same country"). A high score is indicative of tolerance. The Cronbach alpha was .76 for international students and .86 for Canadian students.

Social Desirability Scale. This scale is an adaptation from the 20 items Impression Management subscale of Paulhus' (1991). It examines whether the respondents were misrepresenting themselves 
in order to manage a desirable self-presentation. Items were rated on a five-point Likert scale, from 1 (not true) to 5 (very true). Cronbach alpha was .63 for international students and .67 for Canadian students. A dichotomous scoring method was used to add one point for every ' 5 ' choice, and were then summed. The minimum score was zero and the maximum was twelve. If the total score was higher than seven, it was deemed that the respondents had a deliberate inflation of self-descriptions and their data was not used. This resulted in deletion of three Canadian participants and eight International students.

\section{Results}

\section{International Students' Results}

Results for international students (means, standard deviations and correlations) are shown in Table 1. For demographic variables, the correlations show that with more time they spent in Canada, they: were more proficient in English; accepting of others (higher score on Tolerance, on Perceived Consequences of Immigration, and on Integration); had higher National Identity; and had more Canadian Peer Contact. But no significant correlations were found between the time they spent in Canada and either psychological adaptation or sociocultural competence. English Proficiency significantly and positively correlated with Self-esteem and Sociocultural Competence.

For the multiculturalism hypothesis, correlations supported this hypothesis: Perceived Discrimination (as an indicator of threat or negative security) had a significant negative correlation with Tolerance. Perceived Discrimination also had significant correlations with all three dimensions from the Acculturation Attitudes scale: positive with Separation and Marginalization and negative with Integration. The other measure of security, Perceived Consequences of Immigration, has a positive correlation with Integration and a negative correlation with Separation and Marginalization.

For the integration hypothesis, correlations partially supported this hypothesis: Integration had significant correlations with Sociocultural Competence and with Tolerance. However, there were no significant relationships with the other adaptation measures (Self-esteem, Life Satisfaction, Anxiety, Depression). The meaning of integration also involves co-ethnic contacts: these had a significant positive correlation with Self-esteem. 
Table 1(a). Means and Standard Deviations of, and Pearson Correlation Coefficients Between, Study Variables, For Chinese International Students

\begin{tabular}{|c|c|c|c|c|c|c|c|c|c|}
\hline & 1 & 2 & 3 & 4 & 5 & 6 & 7 & 8 & 9 \\
\hline $\begin{array}{l}\text { 1. Time being in Canada (in } \\
\text { months) }\end{array}$ & 1 & & & & & & & & \\
\hline 2.English proficiency & $.33^{*}$ & 1 & & & & & & & \\
\hline 3.Perceived discrimination & -.01 & -.23 & 1 & & & & & & \\
\hline $\begin{array}{l}\text { 4.Perceived consequences of } \\
\text { immigration }\end{array}$ & $.37^{*}$ & $.48^{* * *}$ & $-.26^{*}$ & 1 & & & & & \\
\hline 5.Integration & $.30^{*}$ & $.48^{* * *}$ & $-.48^{* * *}$ & $.46^{* * *}$ & 1 & & & & \\
\hline 6.Separation & .14 & $-.38^{* *}$ & $.32^{*}$ & $-.38^{* *}$ & $-.47^{* * *}$ & 1 & & & \\
\hline 7.Marginalization & -.04 & -.26 & $.45^{* * *}$ & -.21 & $-.53^{* * *}$ & $.50^{* * *}$ & 1 & & \\
\hline 8. National identity & $.30^{*}$ & $.43^{* *}$ & -.15 & .06 & $28^{*}$ & -.26 & -.23 & 1 & \\
\hline 9.Ethnic identity & .20 & .20 & -.20 & .05 & .22 & .05 & -.15 & .05 & 1 \\
\hline 10.Co-ethnic contact $(n=56)$ & .11 & .21 & -.10 & .09 & .18 & .10 & -.10 & -.02 & $.30^{*}$ \\
\hline $\begin{array}{l}\text { 11.Other ethnic contact } \\
(n=53)\end{array}$ & .26 & .18 & .01 & .09 & .25 & -.01 & -.14 & .24 & .23 \\
\hline 12. Canadian contact $(n=52)$ & $.42^{* *}$ & $.35^{* *}$ & -.20 & .05 & $.44^{* *}$ & -.08 & $-.33^{*}$ & .26 & $.36^{*}$ \\
\hline 13.Self-esteem & -.10 & .10 & -.12 & $.30^{*}$ & .25 & -.09 & -.10 & .00 & -.06 \\
\hline 14.Life satisfaction & -.02 & -.23 & -.10 & -.09 & -.05 & -.06 & .00 & -.01 & .24 \\
\hline 15.Anxiety & .02 & -.22 & -.06 & -.01 & .00 & .14 & .09 & -.01 & .07 \\
\hline 16.Depression & .05 & $.39^{* *}$ & -.02 & -.15 & .01 & .21 & .08 & .00 & .13 \\
\hline 17.Sociocultural competence & .18 & 3.8 & $-.37^{* *}$ & $.44^{* *}$ & $.40^{* *}$ & $-.27^{*}$ & $-.38^{* *}$ & .10 & -.05 \\
\hline 18.Tolerance & $.32^{*}$ & $.43^{* *}$ & $-.37^{* * *}$ & $.60^{* * *}$ & $.57^{* * * *}$ & $-.43^{* *}$ & $-.46^{* * * *}$ & -.04 & .20 \\
\hline Mean & 13.4 & (0.6) & 1.9 & 3.6 & 4.4 & 2.3 & 1.8 & 2.2 & 4.4 \\
\hline SD & 17.1 & 1 & $(0.7)$ & $(0.5)$ & (0.6) & $(0.7)$ & $(0.8)$ & (1.0) & $(0.7)$ \\
\hline
\end{tabular}


Table 1(b). Means and Standard Deviations of, and Pearson Correlation Coefficients Between, Study Variables, For Chinese International Students

\begin{tabular}{|c|c|c|c|c|c|c|c|c|c|}
\hline & 10 & 11 & 12 & 13 & 14 & 15 & 16 & 17 & 18 \\
\hline 10.Co-ethnic contact $(n=56)$ & 1 & & & & & & & & \\
\hline 11.Other ethnic contact $(n=53)$ & $.42^{* *}$ & 1 & & & & & & & \\
\hline 12. Canadian contact $(n=52)$ & $.55^{* * *}$ & $.60^{* * *}$ & 1 & & & & & & \\
\hline 13.Self-esteem & $.27^{*}$ & .20 & .20 & 1 & & & & & \\
\hline 14.Life satisfaction & .24 & $.28^{*}$ & .23 & $.28^{*}$ & 1 & & & & \\
\hline 15.Anxiety & -.25 & -.08 & -.15 & $.41^{* *}$ & $-.34^{*}$ & 1 & & & \\
\hline 16.Depression & -.22 & $-.32^{*}$ & -.10 & $-.37^{* *}$ & $-.38^{* *}$ & $.75^{* * *}$ & 1 & & \\
\hline 17. Sociocultural competence & .07 & .04 & .26 & $.39^{* *}$ & .09 & -.15 & -.24 & 1 & \\
\hline 18.Tolerance & .07 & .17 & .21 & .24 & .12 & -.01 & -.06 & $.29^{*}$ & 1 \\
\hline Mean & 4.0 & 2.4 & 2.4 & 3.8 & 3.4 & 2.2 & 2.1 & 1.9 & 4.0 \\
\hline SD & $(0.7)$ & $(1.1)$ & $(1.2)$ & $(0.5)$ & $(0.7)$ & $(0.6)$ & $(0.5)$ & $(0.7)$ & $(0.5)$ \\
\hline
\end{tabular}

We conducted cluster analyses, using standardized scores, and the k-means method to generate acculturation strategy clusters, for international students and Canadian students separately (see Figure 1). For international students, variables included Acculturation Attitude (Integration, Separation and Marginalization), Peer Contacts (Canadian, co-ethnic, and other-ethnic) and Cultural Identity (national and ethnic). Based on the interpretability of the result, two clusters were identified (five cases were excluded from cluster analysis since there were missing values in Peer Contact): integration cluster $(n=36)$ and diffuse cluster $(n=16)$. The integration cluster corresponded to the integration strategy, while the diffuse cluster combined characteristics of both the marginalization and separation strategies. As shown in Figure 1, those in the integration cluster scored higher than average on the Integration acculturation attitude, much lower than the average score on Marginalization, and a small deviation from average on Separation. They scored higher than average on Canadian Contact, and Co-ethnic Contact (which taken together are indicators of integration) and on Ethnic Identity (but not on National Identity). For the diffuse cluster, international students scored high on both Separation and Marginalization, and low on Integration; they also scored lower than average on all Peer Contact measures and on both Cultural Identity scales. 
Figure 1. Cluster analysis result based on Acculturation Attitude, Cultural Identity and Peer Contact for international students.

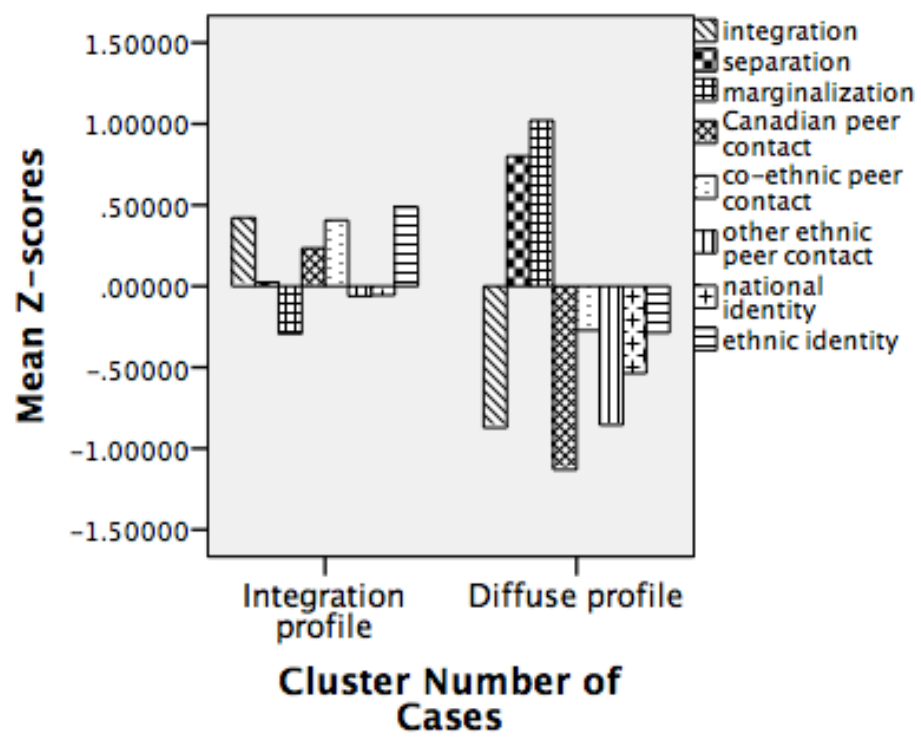

Table 2 shows the differences between students in the two clusters by comparing them with one tailed $t$ test, Integration cluster students were those who had spent more time in Canada, and were more proficient in English. With respect to the multiculturalism hypothesis, Integration cluster students scored lower on Perceived discrimination than those in the Diffuse cluster. With respect to the integration bypothesis, those in the Integration cluster had a higher score on Sociocultural Competence, but there were no differences on Psychological Adaptation. They also had better intercultural adaptation, scoring higher on Tolerance.

Table 2. T Test Comparisons According To International Students' Cluster Membership.

\begin{tabular}{llllc}
\hline & $\begin{array}{l}\text { Integration cluster } \\
(n=36)\end{array}$ & $\begin{array}{l}\text { Diffuse cluster } \\
(n=16)\end{array}$ & $t$ & $p$ (1_tailed) \\
\hline Time being in Canada & $17.7(20.3)$ & $6.1(3.3)$ & 3.35 & 0.001 \\
English proficiency & $3.9(0.5)$ & $3.5(0.6)$ & 2.68 & 0.005 \\
Perceived discrimination & $1.8(0.6)$ & $2.4(0.8)$ & 2.84 & 0.004 \\
Perceived consequences of immigration & $3.7(0.4)$ & $3.5(0.6)$ & 1.25 & 0.108 \\
Self-esteem & $3.8(0.5)$ & $3.7(0.6)$ & 0.43 & 0.335 \\
Life satisfaction & $3.5(0.8)$ & $3.4(0.6)$ & 0.37 & 0.357 \\
PS_anxiety & $2.3(0.7)$ & $2.3(0.7)$ & 0.19 & 0.426 \\
PS_depression & $2.1(0.5)$ & $2.2(0.6)$ & 0.66 & 0.255 \\
Sociocultural competence & $3.3(0.5)$ & $2.7(0.9)$ & 2.47 & 0.012 \\
Tolerance & $4.1(0.4)$ & $3.6(0.7)$ & 2.66 & 0.008 \\
\hline
\end{tabular}




\section{Canadian Students' Results}

The correlations, means and standard deviations for Canadian students are shown in Table 3. The multiculturalism hypothesis proposes that those who feel secure in their society will be more accepting of others. Canadian students' Cultural Security and Perceived Consequences of Immigration scores had significant negative correlations with acceptance of Melting Pot. There were also significant correlations with all scales measuring their acceptance of others (including Multicultural Ideology, Tolerance). The integration hypothesis proposes that those who adopt a Multicultural expectation will have greater wellbeing. Correlations supported this hypothesis with a significant relationship between Multiculturalism and three psychological adaptation scales (including Self-esteem, Anxiety, and Depression); however there was no relationship with Life Satisfaction.

Table 3. Means and Standard Deviations of, and Pearson Correlation Coefficients Between, Study Variables for Canadian Students

\begin{tabular}{|c|c|c|c|c|c|c|c|c|c|c|c|c|c|}
\hline & 1 & 2 & 3 & 4 & 5 & 6 & 7 & 8 & 9 & 10 & 11 & 12 & 13 \\
\hline 1.Cultural Security & 1 & & & & & & & & & & & & \\
\hline $\begin{array}{l}\text { 2.Perceived } \\
\text { Consequences of } \\
\text { Immigration }\end{array}$ & $.62^{* * *}$ & 1 & & & & & & & & & & & \\
\hline 3.National Identity & -.03 & -.17 & 1 & & & & & & & & & & \\
\hline 4. Melting pot & $-.61^{* * *}$ & $-.69^{* * *}$ & .05 & 1 & & & & & & & & & \\
\hline 5.Multicultualism & -.18 & -.09 & $.24^{*}$ & .12 & 1 & & & & & & & & \\
\hline $\begin{array}{l}\text { 6.Other Ethnic } \\
\text { Contacts }\end{array}$ & .04 & .14 & .08 & -.19 & .05 & 1 & & & & & & & \\
\hline $\begin{array}{l}\text { 7.Canadian } \\
\text { Contacts }\end{array}$ & .05 & -.02 & $.39^{* *}$ & -.08 & -.03 & $.33^{* *}$ & 1 & & & & & & \\
\hline 8.Self-esteem & -.04 & -.02 & .08 & .06 & $.41^{* *}$ & -.02 & -.02 & 1 & & & & & \\
\hline 9.Life Satisfaction & .02 & .01 & $.26^{*}$ & .05 & .22 & .07 & $.24^{*}$ & $.54^{* * *}$ & 1 & & & . & \\
\hline 10.Anxiety & .09 & .03 & -.10 & -.06 & $-.28^{*}$ & .05 & -.03 & $-.56^{* * *}$ & $-.33^{* *}$ & 1 & & & \\
\hline 11.Depression & .14 & -.02 & -.02 & -.09 & $-.27^{*}$ & .04 & -.13 & $-.57^{* * *}$ & $-.36^{* *}$ & $.86^{* * *}$ & 1 & & \\
\hline $\begin{array}{l}\text { 12.Multicultural } \\
\text { Ideology }\end{array}$ & $.76^{* * *}$ & $.72^{* * * *}$ & -.09 & $-.69^{* * *}$ & -.18 & .15 & .11 & -.02 & 18 & .06 & .04 & 1 & \\
\hline 13.Tolerance & $.58^{* * *}$ & $.76^{* * *}$ & -.09 & $-.61^{* * *}$ & -.05 & .13 & -.04 & .07 & .01 & -.06 & -.10 & $.62^{* * *}$ & 1 \\
\hline Mean & 4.0 & 3.6 & 4.8 & 2.0 & 4.2 & 3.2 & 4.4 & 4.1 & 3.6 & 2.6 & 2.3 & 3.8 & 4.2 \\
\hline SD & $(0.7)$ & (0.6) & $(0.5)$ & (0.6) & (0.6) & $(1.2)$ & $(0.7)$ & (0.6) & (0.8) & (0.8) & (0.7) & (0.7) & (0.6) \\
\hline
\end{tabular}


Cluster analysis was also carried out with the Canadian student sample, using, the k-means method and standardized scores with the variables of Multiculturalism, Melting Pot and other ethnic Peer Contact. Figure 2 shows the two clusters of Multiculturalism $(n=38)$ and Melting Pot $(n=30)$. The variable of National Identity and Canadian Peer Contact were not included in the cluster analysis since Canadian students had very high scores on these variables, yielding a ceiling effect. Canadian students who were in the multiculturalism cluster had a higher than average score on the Multiculturalism expectation and a lower score on Melting Pot; they also had a higher than average score on Other Ethnic Peer Contact. Those in the melting pot cluster scored higher on Melting Pot and lower on Multiculturalism; they also reported lower than average Other Ethnic Peer Contacts.

Figure 2. Cluster analysis result based on Acculturation Expectation and Peer Contact for Canadian students.

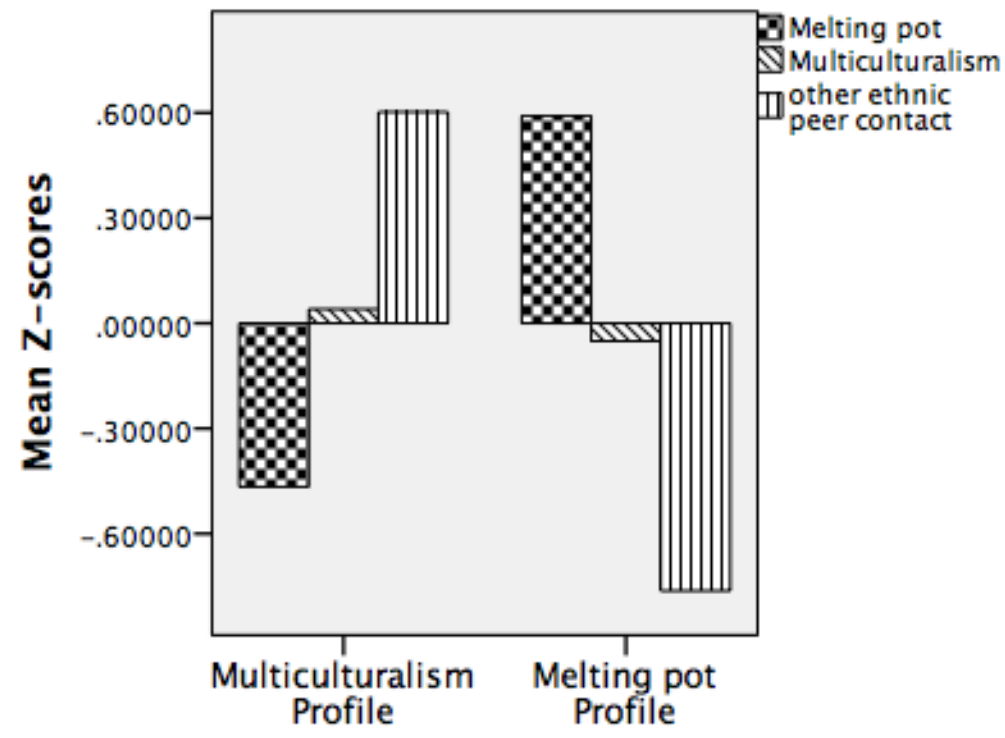

Cluster Number Cases

Comparing the other variables between these two clusters using a one tailed t-test, we can evaluate the multiculturalism and integration hypotheses. For the multiculturalism hypothesis, Canadian students in the multiculturalism cluster had higher Cultural Security and Perceived consequences of immigration scores. For the integration hypothesis, Canadian students in the multiculturalism cluster had a significantly higher score on Life Satisfaction, had significantly better intercultural adaptation (significantly higher scores on Multicultural Ideology and Tolerance); they had more Canadian peer contact, but there were no differences on the other measures of psychological wellbeing (Self-esteem, Anxiety and Depression). 
Table 4. T Test Comparisons According To Canadian Students' Cluster Membership.

\begin{tabular}{lllll}
\hline & $\begin{array}{l}\text { Multiculturalism cluster } \\
(38)\end{array}$ & $\begin{array}{l}\text { Melting pot cluster } \\
(30)\end{array}$ & $\mathrm{t}$ & $\begin{array}{l}\mathrm{p} \\
(1 \text {-tailed })\end{array}$ \\
\hline Cultural security & $4.2(0.5)$ & $3.9(0.7)$ & 2.14 & 0.018 \\
$\begin{array}{l}\text { Perceived consequences of } \\
\text { immigration }\end{array}$ & $3.7(0.5)$ & $3.3(0.6)$ & 2.96 & 0.002 \\
National identity & $4.9(0.3)$ & $4.7(0.6)$ & 1.35 & 0.092 \\
Canadian contacts & $4.6(0.6)$ & $4.2(0.7)$ & 2.26 & 0.014 \\
Self-esteem & $4.1(0.7)$ & $4.0(0.6)$ & 0.72 & 0.238 \\
Life satisfaction & $3.7(0.7)$ & $3.4(0.9)$ & 1.69 & 0.048 \\
Anxiety & $2.6(0.8)$ & $2.7(0.7)$ & 0.18 & 0.431 \\
Depression & $2.3(0.8)$ & $2.4(0.7)$ & & \\
Multicultural Ideology & $4.1(0.5)$ & $3.5(0.7)$ & 3.53 & 0.298 \\
Tolerance & $4.5(0.5)$ & $4.0(0.7)$ & 3.41 & 0.001 \\
\hline
\end{tabular}

\section{Discussion}

Based on the Likert scale scores (which range from 1 to 5), our results indicate that International students perceive a low level of discrimination (score of 1.9 on Perceived Discrimination) and they endorse Integration as a way to live in Canada (4.4). Canadians students feel secure in their cultural identity (4.0 on Cultural Security) and endorse Multiculturalism (4.2). There is an apparent high degree of acceptance of people with different ethnicity in the two samples. This overall satisfaction with Canadian experience has been reported by other authors. For example, in a qualitative study in Canada, Scott, Safdar, Desai Trilokekar, and El Masri (2015) found that international students report low discrimination and are highly engaged with services at their university campuses.

However, although there is a high mean level of acceptance of others in these two samples, both correlational and cluster analyses revealed significant individual differences within the samples. Cluster analysis provided evidence that international students were divided into an integration cluster and a diffuse cluster: Canadian students were divided to a multiculturalism cluster and a melting pot cluster.

Comparisons between two clusters for both the international students and Canadian students support the multiculturalism bypothesis. International students in the integration cluster were those who perceived less discrimination, and they also had a higher score on Tolerance. Our findings confirm earlier research that when there is little perception of discrimination, newcomers are more likely to 
endorse the integration strategy (Berry et al., 2006), while threatening an individual's or group's identity is likely to lead to hostility (Berry, 2013). Canadian students in the multiculturalism cluster were those who had higher Cultural Security, and scored higher on Multicultural Ideology, Tolerance, and Perceived Consequences of Immigration. Consistent with previous findings, the more secure the Canadian students felt, the higher was their acceptance of others (such as Tolerance; see Lebedeva \& Tatarko, 2013), and the more positive were their attitudes toward immigrants (see Ward \& Masgoret, 2008).

Support for the integration hypothesis was also provided by the cluster analysis. For international students, those in the integration cluster had higher Sociocultural Competence scores than students in diffuse cluster. This result is consistent with Ward and Kennedy's (1994) research with sojourners in New Zealand; they found that the greatest amount of social difficulty was experienced by respondents who endorsed a separatist orientation, and the least by those who endorsed the assimilation and integration. For Canadian students, those in the multiculturalism cluster had higher Life Satisfaction than those in the melting pot cluster. This finding could indicate that Canadian students who support the national policy of multiculturalism feel in harmony with the larger society and are feeling well about living in Canada. In comparisons of other psychological adaptation measures none reached significance; however, there were no contradictory findings. Overall, the results indicate that for international students, integration is the better acculturation strategy, while being diffuse (combining a preference for separation and marginalization) is a worse strategy. This finding is consistent with much previous research with immigrant samples (reviewed by Berry, 1997; Nguyen \& Benet-Martinez, 2013). It is also consistent with the findings that assimilation (Safdar, Lay, \& Struthers, 2003) or positive attitudes toward new culture acquisition (Safdar, Struthers, \& van Oudenhoven, 2009) is positively related to sociocultural adaptation.

Our results indicate some similarities between international and Canadian students in terms of the multiculturalism and integration hypotheses. That is, those who are secure in their culture and identity are more tolerant toward others, and those who endorse integration or multiculturalism have better psychological or sociocultural adaptation. This shared pattern of findings provides a research basis for promoting positive intercultural relations in Canada through integration and multiculturalism. If they had differed, it would be difficult to engage in a common program to achieve mutual adaptation and acceptance between international and domestic students. We suggest providing increased opportunities for international and domestic students to be exposed to each other's norms and values, and thereby to develop a mutual appreciation of their respective cultures. Additionally, as international students become more confident with their language and communication proficiency, they will likely gain more assurance to integrate into the Canadian society. Our findings are not only consistent with much previous research (e.g., CBIE, 2014), they also enhance the existing literature because no study, to our knowledge, has conducted comparative analyses examining these hypotheses with both international and domestic students.

\section{Limitations}

There are some limitations to our research. First, our sample was a sample of convenience rather than a representative sample of students, nor of the population. Second, our international student sample was heterogeneous: they included both graduate and undergraduate students, those who were studying English before entering university, and were from different universities. These students thus 
had different experiences according to different courses, different universities and different cities within Canada, all of which could be reflected in their attitudes toward the Canadian society. Future research should devote more effort to obtaining a more representative and more homogeneous student sample. Despite these limitations, we believe our study contributes to understanding the intercultural relations and adaptation of both international and domestic university students in Canada.

\section{Acknowledgments}

Work by John Berry on this study has been supported by the grant of Russian Science Foundation (project № 15-18-00029). Work by Yongxia Gui on this study has been supported by China Scholarship Council.

\section{References}

Ayres, C.G., \& Mahat, G. (2012). Social Support, Acculturation, and Optimism: Understanding Positive Health Practices in Asian American College Students. Journal of Transcultural Nursing, 23(3): 270-278.

Berry, J. W. (1980). Acculturation as varieties of adaptation. In A. Padilla (Ed.), Acculturation: Theory, models and some new findings (pp. 9-25). Boulder: Westview.

Berry, J. W. (1997). Immigration, acculturation and adaptation. Applied Psychology: An International Review, 46(1): 5-34.

Berry, J.W. (2003). Conceptual approaches to acculturation. In K. Chun, P. Balls-Organista, \& G. Marin (Eds.), Acculturation: Advances in theory, measurement and application (pp. 17-37). Washington: APA Books.

Berry, J.W. (2013). Research on multiculturalism in Canada. International Journal of Intercultural Relations, 37: 663-675.

Berry, J.W. (2015). Intercultural adaptation to acculturation. Paper presented to the Canadian Psychological Association, Ottawa, June.

Berry, J.W., \& Kalin, R. (1995). Multicultural and ethnic attitudes in Canada: An overview of the 1991 national survey. Canadian Journal of Behavioral Science, 27: 301-320.

Berry, J.W., Kalin, R., \& Taylor, D. (1977). Multiculturalism and ethnic attitudes in Canada. Ottawa, ON: Supply \& Services.

Berry, J. W., Phinney, J. S., Sam, D. L., \& Vedder, P. (2006). Immigrant youth: Acculturation, identity, and adaptation. Applied Psychology: An International Review, 55(3): 303-332.

CBIE (Canadian Bureau for International Education, 2014). A World of Learning: Canada's Performance and Potential in International Education. ISSN: 2292-1966

Castillo, L.G., Conoley, C.W., \& Brossart, D. F. (2004). Acculturation, white marginalization and family support as predictors of perceived distress in Mexican American Female College Students. Journal of Counseling Psychology, 51 (2): 151-157.

Chavajay, P., \& Skowronek, J. (2008). Aspects of acculturation stress among international students attending a university in the USA. Psychological Reports, 103: 827-835.

Citizenship and Immigration Canada. (n.d.). Glossary: international student. Retrieved from http://www.cic.gc.ca/english/helpcentre/glossary.asp\#foreign_student

Citizenship and Immigration Canada. (2014). International students with a valid permit on December 31 st by gender and age, 1994 to 2013. Retrieved from http:/ / www.cic.gc.ca/english/resources/statistics/facts2013/temporary/4-1.asp\#fig5

Citizenship and Immigration Canada. (2015). International students by top 50 countries of citizenship and sign year, 2004 to 2013. Retrieved from 
http://www.cic.gc.ca/english/resources/statistics/facts2013/temporary/6-1.asp

Dao, T. K., Lee, D., \& Chang, H. L. (2007). Acculturation level, perceived English fluency, perceived social support level, and depression among Taiwanese international students. College Student Journal, $41(2):$ 287-295.

Diener, E., Emmons, R. A., Larson, R. J., \& Griffin, S. (1985). The satisfaction with life scale. Journal of Personality Assessment, 49(1): 71-75.

Esses, V.M., Hodson, G., \& Dovidio, J.F. (2003). Public attitudes toward immigrants and immigration: Determinants and policy implications. In C.M. Beach, A.G. Green, \& J.G. Reitz (Eds.), Canadian immigration policy for the 21st century (pp. 507- 535). Montreal, Canada: McGill Queen's Press.

Gareis, E. (2012). Intercultural Friendship: Effects of Home and Host Region. Journal of International and Intercultural Communication, 5 (4), 309-328. DOI: 10.1080/17513057.2012.691525

Gui, Y., Berry, J.W., \& Zheng, Y. (2012). Migrant worker acculturation in China. International Journal of Intercultural Relations, 36: 598-610.

Lebedeva, N. M., \& Tatarko, A.N. (2013). Multiculturalism and immigration in post-Soviet Russia. European Psychologist, 18: 169-178.

Nguyen, A.-M. D., \& Benet-Martinez, V. (2013). Biculturalism and adjustment: A meta analysis. Journal of Cross-Cultural Psychology, 44: 122-159.

Paulhus, D. L. (1991). Measurement and control of response bias. In J. P. Robinson, P. R. Shaver, \& L. S. Wrightsman (Eds.), Measures of personality and social psychological attitudes (pp. 17-59). San Diego, CA: Academic Press.

Redfield, R., Linton, R., \& Herskovits, M. J. (1936). Memorandum for the study of acculturation. American Antbropologist, 38 (1), 149-152.

Rosenberg, M. (1965). Society and the adolescent child. Princeton, NJ: Princeton University Press.

Safdar, S. \& Berno, T. (in press). Sojourners: The experience of expatriates, students, and tourists (Chapter 10). In D.L. Sam \& J.W. Berry (Eds.), The Cambridge Handbook of Acculturation Psychology $\left(2^{\text {nd }}\right.$ edition). Cambridge: Cambridge University Press.

Safdar, S., Calvez, S., \& Lewis, J.R. (2012). Multi-group analysis of the MIDA model: acculturation of Indian and Russian immigrants in Canada. International Journal of Intercultural Relation, 36(2): 200212.

Safdar, S., Choung, K., \& Lewis, J.R. (2013). A review of the MIDA model and other contemporary acculturation models. In E. Tartakovsky (Ed.), Immigration: policies, challenges and impact. (213-230). Hauppauge, NY: Nova Science Publisher.

Safdar, S., Lay, C., \& Struthers, W. (2003). The process of acculturation and basic goals: Testing a Multidimensional Individual Difference Acculturation Model with Iranian immigrants in Canada. Applied Psychology: An International Review, 52(4): 555-579.

Safdar, S., Struthers, W., \& van Oudenhoven, J. P. (2009). Acculturation of Iranians in the United States, the United Kingdom, and the Netherlands. Journal of Cross-Cultural Psychology, 40(3): 468491.

Scott, C., Safdar, S., Desai Trilokekar, R., \& El Masri' A. (2015). International Students as 'Ideal Immigrants' in Canada: A disconnect between policy makers' assumptions and the lived experiences of international students. Comparative and International Education. 43(3), Article 5. Available at: http://ir.lib.uwo.ca/cie-eci/vol43/iss3/5

Ward, C., \& Kennedy, A. (1994). Acculturation Strategies, psychological adjustment, and sociocultural competence during cross-cultural transitions. International Journal of Intercultural Relations, 18 (3): 329-343.

Ward, C., \& Kennedy, A. (1999). The measurement of sociocultural adaptation. International Journal of Intercultural Relations, 23: 659-677. 
Ward, C., \& Masgoret, A.-M. (2008). Attitudes toward immigrants, immigration and multiculturalism in New Zealand: A social psychological analysis. International Migration Review 42: 222-243.

Zhang, N., \& Dixon, D. N. (2003). Acculturation and attitudes of Asian international students toward seeking psychological help. Journal of Multicultural Counseling and Development, $31: 205-222$. 